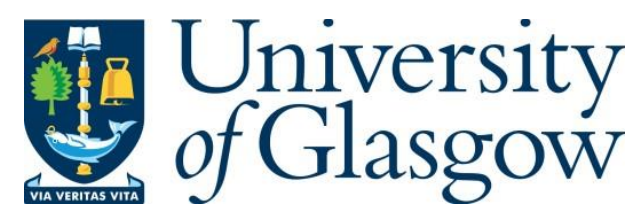

Böhm, M. et al. (2016) Non-adherence to ivabradine and placebo and outcomes in chronic heart failure: an analysis from SHIFT. European Journal of Heart Failure, 18(6), pp. 672-683.

There may be differences between this version and the published version. You are advised to consult the publisher's version if you wish to cite from it.

http://eprints.gla.ac.uk/121621/

Deposited on: 20 September 2017

Enlighten - Research publications by members of the University of Glasgow http://eprints.gla.ac.uk 


\section{Non-adherence to ivabradine and placebo and outcomes in chronic heart failure An analysis from the SHIFT}

Michael Böhm; Suzanne M. Lloyd2; Ian Ford2; Jeffrey S. Borer³ Sebastian Ewen; Ulrich Laufs ${ }^{1}$; Felix Mahfoud1; Jose Lopez-Sendon4; Piotr Ponikowski5; Luigi Tavazzi ${ }^{6}$; Karl Swedberg7; Michel Komajda8

\section{Address for correspondence:}

Michael Böhm, MD

Universitätsklinikum des Saarlandes

Klinik für Innere Medizin III

Kardiologie, Angiologie und Internistische Intensivmedizin 0

Kirrberger Str. 1

D-66424 Homburg/Saar

Germany

Tel.: (+49)-6841-16-23372

Fax: (+49)-6841-16-23369

E-mail: michael.boehm@uks.eu

${ }^{1}$ Universitätsklinikum des Saarlandes, Klinik für Innere Medizin III, Homburg/Saar, Germany

${ }^{2}$ Robertson Centre for Biostatistics, University of Glasgow, Glasgow, UK

${ }^{3}$ Division of Cardiovascular Medicine, The Howard Gilman Institute for Heart Valve Diseases and the Schiavone Institute for Cardiovascular Translational Research, SUNY Downstate Medical Center, Brooklyn and New York, NY, USA

${ }^{4}$ Hospital Universitario La PAZ, Cardiology Department, Instituto de Investigation, Madrid, Spain

${ }^{5}$ Department of Cardiology, Military Hospital, Wrocław, Poland

${ }^{6}$ Maria Cecilia Hospital - GVM Care \& Research - E.S. Health Science Foundation, Cotingola, Italy

${ }^{7}$ Department of Molecular and Clinical Medicine, Sahlgrenska Academy, University of Gothenburg, Sweden and National Heart and Lung Institute, Imperial College, London

8 Institute of Cardiometabolism and Nutrition (ICAN), Pierre et Marie Curie Paris VI University, La Pitié-Salpétrière Hospital, Paris, France 


\section{Abstract}

Aims - In heart failure non-adherence increases events, in turn, the effect of hospitalization on adherence is incompletely understood. We explored the relationship of non-adherence with outcomes, hospitalizations with non-adherence and the influence of non-adherence on treatment effects of heart rate lowering with ivabradine.

Methods and results - In the randomized, controlled Systolic Heart failure treatment with the If-inhibitor ivabradine Trial (SHIFT), we studied the effect of non-adherence $(\mathrm{N}=1287)$ compared to adherent patients $(\mathrm{N}=5204)$ on cardiovascular outcomes. After adjustment, non-adherence was associated with the primary composite endpoint of cardiovascular death and heart failure hospitalization (hazard ratio 3.47, 2.91-4.13, $p<0.0001$ ). No interaction with the treatment groups of placebo or ivabradine ( $p$ for interaction 0.54) occured. Similar results for cardiovascular death, heart failure hospitalization as well as for cardiovascular hospitalization, heart failure death and total death were observed. The effect of ivabradine was maintained in patients being adherent or becoming non-adherent during the trial ( $p$ for interaction $=0.54$ ). Patients with a previous hospitalization were more likely to become non-adherent thereafter.

Conclusions - Non-adherence identifies a group at particularly high cardiovascular event risk independent of treatment allocation. Non-adherent patients in the ivabradine group maintain a treatment benefit. Patients with previous hospitalizations are more likely to become non-adherent and represent a group of particular high risk patients in whom special attention to stimulate adherence may be valuable.

Clin Trial Registration - URL: http:/www.clinicaltrials.gov. Unique identifier ISRCTN70429960.

Key words: heart failure - SHIFT - heart rate - adherence - cardiovascular hospitalizations 


\section{Introduction}

Chronic heart failure is highly prevalent in the United States (1) and Europe (2). Its prevalence is associated with age and increases to $\geq 10 \%$ at the age of 80 years and older (3). Evidence has shown that certain treatments reduce morbidity and mortality (2). However, adherence to these medical therapies has been limited, apparently occurring in $40-60 \%$ of patients with heart failure (4) and other chronic diseases, in which long-term therapies are indicated (5). Non-adherence to medication is related to poor outcomes in various conditions like heart failure (4), in high risk settings after vascular events (6), hypertension $(7,8)$, after myocardial infarction (9) and in patients on oral anticoagulation (10). Non-adherence is also a common precipitant for heart failure readmissions (11). In clinical trials, non-adherence to study medications with statins (12), beta blockers (13), anti-hypertensive agents $(7,8,14)$ and inhibitors of the renin-angiotensin system (6) are associated with cardiovascular complications, the effect being similar to investigations outside clinical trials $(5,11)$. Non-adherence to medical interventions in general, including placebo applications, has impacted outcomes $(15,16)$. This effect, referred to as the "healthy adherer phenomenon" is associated with adverse health care behaviors and related to the fact of being nonadherent to any medical advice or intervention $(15,16)$. In this analysis of the Systolic Heart failure treatment with the If-inhibitor Trial (SHIFT), we investigated the effects of adherence in patients on the study medications ivabradine or placebo. SHIFT investigated the effect of heart rate reduction in 6505 patients with systolic heart failure and a heart rate of $\geq 70 \mathrm{bpm}$ in sinus rhythm and receiving evidence-based contemporary medical treatments (17). We looked at outcomes on placebo and ivabradine in adherent and non-adherent patients and also investigated whether, after a nonfatal hospitalization, the rate of non-adherence is changed. 


\section{Methods}

\section{Study design and study population}

SHIFT was a randomized, double-blind, placebo controlled outcomes trial in patients with sinus rhythm and chronic moderate to severe heart failure. Patients were included with a resting heart rate $\geq 70 \mathrm{bpm}$ in sinus rhythm and an ejection fraction $\leq$ $35 \%$. In 37 countries (677 medical centers), a total of 6505 patients were randomized to either placebo or ivabradine with a starting dose of $5 \mathrm{mg}$ bid, which could be uptitrated to $7.5 \mathrm{mg}$ bid or reduced to $2.5 \mathrm{mg}$ bid after a titration interval of 28 days; upor down-titration dependent on achieved heart rate and tolerability of the study drug. Heart rate was measured on two consecutive visits prior to randomization by a 12lead electrocardiogram, which was repeated at baseline and at every follow-up visits during the study period. The design (17) and the primary results (18) have been reported previously. All outcomes were confirmed by an Adjudication Committee according to described criteria (17). SHIFT showed that heart rate reduction with the If-inhibitor ivabradine reduced the composite of cardiovascular death and heart failure hospitalization in patients at a heart rate $\geq 70 \mathrm{bpm}$ (18). In patients with a heart rate $\geq$ $75 \mathrm{bpm}$ cardiovascular death and all-cause death (19) also were reduced. Lowest event rates were achieved when heart rate on drug fell below $60 \mathrm{bpm}(20)$.

\section{Procedures}

Study personnel recorded adherence as the number of blinded study pills taken as a proportion of those distributed according to the protocol. This procedure was done at each follow-up visit, which took place after inclusion, at day 14 , at day 28 , at 4 months and every 4 months thereafter until the final visit (e.g., month 48). Adherence was defined as being on the study medication (active drug or placebo) throughout the 
total period of the study, while non-adherence was defined as premature and permanent stopping of either study drug (ivabradine or placebo). Temporary interruptions of study drugs were not regarded as being non-adherent, because investigators and patients were advised to reintroduce study medications in case of temporary interruptions.

\section{Patients}

We explored the baseline characteristics in adherent and non-adherent patients according to demography, cardiac parameters, medical history and concomitant medications, for all patients and separately by treatment group. Secondly, we looked at the time dependence of becoming non-adherent on placebo or ivabradine in each of the treatment groups. Finally, the following cardiovascular outcomes were tabulated separately in patients adherent or non-adherent to ivabradine or placebo: the SHIFT primary composite of cardiovascular death and heart failure hospitalization, the individual components of the primary composite, total death, heart failure death and cardiovascular hospitalizations. All events in the non-adherent group and adherent group were analyzed at each assessment point during the trial or after the patients had stopped study medication. It was observed that several patients withdrew from study medication because of an event. Therefore, we set out to investigate the effect of non-fatal events on the subsequent occurrence of nonadherence to study drugs. Finally, the treatment effect of ivabradine was assessed as a function of adherence or non-adherence to study drug.

\section{Statistical analysis}

Descriptive statistics are presented as median or mean \pm standard deviation (SD) for continuous variables and as numbers and percentages for categorical variables. 
Patients were divided into those adherent and non-adherent to study medication. Statistics in these groups were tested for differences using analysis of variance for continuous data and $\mathrm{chi}^{2}$ for categorical data. Variation of events across the groups was tested in a Cox proportional hazard model adjusted for beta blocker use, New York Heart Association class, left ventricular ejection fraction, ischemic heart failure, age, estimated glomerular filtration rate, body mass index, history of diabetes, and baseline heart rate. Hazard ratios were calculated with reference to the lowest test groups. SAS (version 9.2) was used for all analyses.

\section{Results}

\section{Patient Characteristics.}

In SHIFT, 6505 patients were randomized to treatment groups (3268 ivabradine, 3290 placebo). For this analysis, data on adherence were available in 6491 patients. 5204 patients were adherent, while 1287 patients were non-adherent, i.e., persistently stopped study medication before their final visit or death. The number of non-adherent patients steadily increased over time. Figure 1 depicts the time to withdrawal from study medications for each of the treatment groups. Slightly more patients in the ivabradine group withdrew from study medication compared to those in the placebo group $(21 \%$ vs $19 \%, p=0.0141)$. Supplement Table 1 summarizes the baseline characteristics by adherence with study medication overall and by treatment group. An increased risk of non-adherence with study medications was associated with older age, lower body mass index, higher heart rate, lower left ventricular ejection fraction, impaired renal function, higher NYHA class, longer duration of heart failure, history of atrial fibrillation, and lower beta blocker use. Formally, statistical differences with device therapies were affected by low numbers of patients. Factors 
associated with non-adherence were similar in patients on ivabradine or placebo (supplement table 1).

\section{Effect of non-adherence}

Figure 2 shows the effect of becoming non-adherent in patients treated with ivabradine or placebo on the primary endpoint (left), heart failure hospitalization (middle) and cardiovascular death (right). For the primary endpoint and its components, there was a markedly higher event rate when patients withdrew from study medication, ivabradine or placebo, compared to when patients adhered to study medication. Nonetheless, the difference between ivabradine and placebo was apparent both in patients who became non-adherent and those who adhered to study drugs. Surprisingly, the difference between ivabradine and placebo was larger in patients who became non-adherent. For cardiovascular death, there was no difference in adherent patients, but there was a difference in the non-adherent patients in favor of ivabradine compared to placebo (Figure 2, right). Similar results were observed for total death (supplement figure 1, left), heart failure death (supplement figure 1, middle) and cardiovascular hospitalization (supplement figure 1 , right). For adherent patients, there was no difference in cardiovascular death (figure 2), total death and heart failure death (supplement figure 1), whereas there was a difference between ivabradine and placebo in non-adherent patients. There was a significant increase of hazard for placebo (Figure 3, left) and ivabradine (Figure 3, right) in non-adherent compared to adherent patients.

Suppl. Figure 2 depicts the event rates in patients who became non-adherent after a cardiovascular event. The differences between adherent and non-adherent patients for the primary endpoint (Suppl. Figure 2, left), heart failure hospitalization (Suppl. 
Figure 2, middle) and cardiovascular death were apparent. Suppl. Figure 3 shows similar results for total death (left), heart failure death (middle) and cardiovascular hospitalization (right). Again, adherence was not associated with any differences in mortality endpoint rates, but a difference between ivabradine and placebo on event rates is apparent once patients become non-adherent. Suppl. Figure 4 shows the hazard ratio for cardiovascular events occurring after study drug withdrawal. On placebo and on ivabradine, the trends for increasing hazard ratios after becoming non-adherent were smaller and were not significantly different on placebo and ivabradine for heart failure hospitalization and cardiovascular hospitalization. However, there was no heterogeneity of the effect of becoming non-adherent after an event on placebo or ivabradine (Suppl. Figure 4).

\section{Treatment effect of ivabradine in adherent and non-adherent patients}

Figure 4 summarizes the effect of ivabradine compared to placebo in patients becoming non-adherent (left) or remaining adherent (right) on the primary composite endpoint (Figure 4A), cardiovascular death (Figure 4B) and heart failure hospitalization (Figure 4C). In adherent patients the overall event rate was lower than in non-adherent patients regardless of assignment to on placebo or ivabradine. Furthermore, the difference between ivabradine and placebo was greater in nonadherent patients while in adherent patients only the primary endpoint cardiovascular death was significantly reduced by ivabradine. Results were similar for total death (Supplement Figure 5A), heart failure death (Supplement Figure 5B) and cardiovascular hospitalization (Supplement Figure 5C) in non-adherent (left) and adherent (right) patients. Treatment effects in non-adherent and adherent patients are summarized in Figure 5. In non-adherent patients (left), the treatment effect of ivabradine was significant for all endpoints while in adherent patients (right) 
significance was demonstrated only on cardiovascular death, heart failure death and total death. However, there was no significant trend for heterogeneity between the treatment effects in the non-adherent and adherent groups.

\section{Effects of hospitalizations on adherence}

To explore the effect of cardiovascular morbidity on adherence, we studied the association of heart failure hospitalization and cardiovascular hospitalizations on becoming non-adherent thereafter. Among all patients becoming non-adherent $(\mathrm{N}=1287), 26.6 \% \quad(\mathrm{~N}=342)$ became non-adherent after a previous heart failure hospitalization, while in the 5204 patients remaining adherent, only $13.6 \%(\mathrm{~N}=705)$ had a previous hospitalization $(p<0.0001)$. Similar results were obtained after separation by treatment groups: $30.3 \%$ of patients on placebo $(\mathrm{N}=183)$ who had previous heart failure hospitalization then became non-adherent; only $15.9 \%(\mathrm{~N}=420)$ of adherent patients had a previous heart failure hospitalization $(p<0.0001)$. Similar results were obtained for ivabradine: $23.3 \%(\mathrm{~N}=159)$ non-adherent and $11.2 \%$ $(\mathrm{N}=285)$ adherent patients experienced a heart failure hospitalization $(\mathrm{p}<0.0001)$. Figure $6 \mathrm{~A}$ provides Kaplan Meier plots for time to permanent study drug withdrawal by previous heart failure hospitalization on placebo (left) and on ivabradine (right). In both treatment strata there was a significant effect $(\log$ rank $<0.0001)$ of heart failure hospitalization on subsequently becoming non-adherent to placebo or ivabradine. Parallel results were obtained for previous cardiovascular hospitalizations (Figure 6B) on placebo (left) or on ivabradine (right). We further explored the hazard of becoming non-adherent by previous heart failure hospitalizations (Figure 7A) or cardiovascular hospitalization (Figure 7B). The results were similar for placebo and for ivabradine and similar for cardiovascular hospitalizations (Figure 7B). In the first 30 days after becoming non-adherent, HR was $71.6 \pm 13.5 \mathrm{bpm}(\mathrm{n}=291)$ on ivabradine and $74.2 \pm$ 
14.0 bpm ( $n=229)$ on placebo. In those becoming non-adherent, HR remained predictive for heart failure hospitalizations after withdrawal of ivabradine (above median 70bpm : 52 (34\%), 30 prior and 23 after becoming non-adherent; below median: 24 (17.8\%), 14 prior, 10 after becoming non-adherent).

\section{Discussion}

The SHIFT database provided the opportunity to study the effect of non-adherence on outcomes and of non-fatal outcomes on non-adherence in a population with systolic heart failure on contemporary guideline-recommended background treatments. The discontinuation of study medication was considered a surrogate for non-adherence to medications in general and the adherence to placebo was considered a surrogate for adherence per se (rather than the effect of the specifically tested drug, ivabradine). We showed that in both groups, randomized to ivabradine or placebo, non-adherence had a strong impact on i) the primary outcome and its components, heart failure hospitalization and cardiovascular death, as well as ii) the secondary outcomes of total death, heart failure death and cardiovascular hospitalizations. The impact was smaller when the effect of non-adherence was evaluated after the patients became non-adherent. The treatment effect of ivabradine was maintained in adherent patients but also in non-adherent patients. Our results extend previous observations showing that patients who experienced a non-fatal hospitalization had an increased rate of becoming non-adherent (6).

\section{Prediction of risk by non-adherence}

Non-adherence to heart failure medications has been associated with higher mortality and increased hospitalizations $(4,5,9,11)$ resulting in increased health care costs $(21,22)$. Non-adherence is related to patient characteristics like age (23), cognitive 
dysfunction and depression $(24,25)$. Since heart failure patients are often elderly with a high load of comorbidities requiring polypharmacy (26) and heart failure therapies are often complex and costly (27), these patients represent a group at particular high risk for non-adherence and subsequently high event rates. This might contribute to the finding that, although several treatments are effective, the mortality and hospitalization rate remains relatively high $(28,29)$. Herein, we observed discontinuation rates of $19 \%$ (placebo) to $21 \%$ (ivabradine) after approximately 1000 days. Our findings are comparable to previous heart failure studies except that, in the earlier studies, a highly variable non-adherence rate was observed (27). This might be due to the fact that under trial conditions more frequent monitoring occurs, which potentially results in a higher adherence rate than in general practice, due to more patient-physician contacts as well as the prescriber continuity in the context of complex treatment regimen (28). As in previous studies (29), it is difficult to distinguish between non-adherence and drug discontinuation by adverse events. The fact that on ivabradine non-adherence was slightly higher than on placebo may be attributable to the relatively smaller portion of patients who discontinued after adverse events on ivabradine compared to placebo, although ivabradine was reported to be well tolerated (18).

\section{Effect of non-adherence on outcomes}

SHIFT patients becoming non-adherent were more likely to develop primary outcomes consisting of cardiovascular death and heart failure hospitalization as well as total death, heart failure death and cardiovascular hospitalizations. Based on the Cox model analyses, there was a difference between patients being off at any time during the follow-up or when events were only counted after patients became nonadherent to study medication. This provides evidence that non-fatal events triggering 
non-adherence might have an important impact on outcomes and non-adherence. Interestingly, as previously observed in the CHARM trial (16), non-adherence was highly prevalent in patients on placebo. This provides evidence that being nonadherent with study medication is a marker of being non-adherent to health care recommendations in general and in particular accompanying heart failure therapies. Heart failure medication other than the study drugs were not captured in SHIfT and also information on drop-in medications was not recorded. Therefore, it is important to know that the non-adherence rate to other drugs such as beta blockers, angiotensin-converting-enzyme-inhibitors/angiotensin receptor-blockers and aldosterone-antagonists might have contributed to the differences between adherent and non-adherent patients on placebo. In support of this notion, non-adherence rates to other medications was reported to be relatively high, amounting to $65 \%$ for beta blockers, $56 \%$ for spironolactone and $79 \%$ for renin-angiotensin antagonists (30). Interestingly, the treatment effect of ivabradine was maintained in non-adherent and adherent patients suggesting that being on a heart rate reducing agent for a short time might provide prolonged beneficial effects on outcome, a finding which is in agreement with the so called "legacy effect" observed in long-term studies with ACEinhibitors (31) and statins (32).

\section{Effect of events on becoming non-adherent}

Patients who experienced a hospitalization subsequently showed a sharp increase in the rate of non-adherence. Therefore, the increased load of morbidity or potentially also a loss of trust in medical interventions might have contributed to this observation. This finding identifies those patients who have suffered a cardiovascular event as a group with particular high risk to become non-adherent and subsequently to experience even more complications. Thus, non-adherence leading to events and 
events leading to non-adherence may be a vicious circle for heart failure patients, creating a particularly high risk. Therefore, special attention must be paid to individuals suffering from a non-fatal event for special strategies to improve medication adherence (33). For example, psychological interventions addressing depressive symptoms and pharmacy based interventions have been shown to improve medication adherence $(33,34,35)$.

\section{Study limitation}

This analysis was performed to identify effects of non-adherence according to study drug withdrawal on cardiovascular outcomes. In this analysis as in studies reported previously $(15,16)$, a strong "healthy adherer effect" was observed. We cannot draw any conclusions on the mechanisms involved in the increased event rates in the placebo group. The effect of withdrawing accompanying heart failure therapies as well as non-adherence to lifestyle recommendations might have contributed. However, these confounders are usually not captured in trial protocols. We defined non-adherence as permanent stop of study medication, while it was defined as being on drug $<80 \%$ of the time in a previous trial (16). However, this approach gets imprecise when patients had only few study visits. Furthermore, phenomena like "drug holidays" and "tooth brushing" effects are not captured by either approach $(8,25)$. Thus, being off study medication is one among other markers of nonadherence. Secondly, this is a retrospective analysis which was not based on randomized comparisons and cannot compare individual drugs, because such an analysis would have been confounded by different known and unknown patients' characteristics or potential differences in the care provided to patients outside the trial. These were not captured in SHIFT, which aimed to investigate the effect of ivabradine on outcomes in individuals with systolic heart failure. Finally, care of these 
patients outside the trial was provided by treating physicians. There might have been a great variety of physician-patient contacts and quality of care in between included patients. Many factors potentially predicting non-adherence like frailty, family support, personality characteristics among many others cannot be captured in a trial like this.

\section{Conclusions}

This analysis of the large SHIFT database shows that non-adherence is a strong predictor of cardiovascular outcomes in patients with heart failure. One important trigger of non-adherence was suffering a non-fatal hospitalization. Patients after a non-fatal event are a particular high risk group at danger of becoming non-adherent and develop consequently more cardiovascular complications thereafter. This group of patients provides a special group at high risk to be targeted by psychological or medical strategies including tight follow-ups to improve medical adherence and to prevent events. The treatment effect of heart rate lowering with ivabradine is maintained in patients who are adherent and who become non-adherent to ivabradine, even though they have not been on the drug for the full study period.

\section{Sources of Funding}

SHIFT was sponsored by Servier, France. All authors received speaking honoraria and/or research support from Servier, France. 


\section{Disclosures}

Michael Böhm reports receiving speaker's fee from Bayer, Boehringer-Ingelheim, Daiichi-Sankyo, Novartis, Pfizer, Servier, Medtronic; Jeffrey Borer performs research and receives honoraria for speaker's bureau from Servier and cunsulting fees and speaker's bureau from Amgen; Michel Komajda is a member of the executive committee of SHIFT and has received fees for speaker's bureau from Sanofi, Novartis, Servier, BMS, Astra Zeneca and Menarini; Luigi Tavazzi has received research grants and honoraria from Servier; Karl Swedberg has received research grants and honoraria for lecturing from Servier; Felix Mahfoud and Sebastian Ewen received research support from Medtronic and St. Jude; Piotr Ponikowski received honoraria from Bayer and Servier. 


\section{References}

1. Roger VL, Go AS, Lloyd-Jones DM, Benjamin EJ, Berry JD, Borden WB, Bravata DM, Dai S, Ford ES, Fox CS, Fullerton HJ, Gillespie C, Hailpern SM, Heit JA, Howard VJ, Kissela BM, Kittner SJ, Lackland DT, Lichtman JH, Lisabeth LD, Makuc DM, Marcus GM, Marelli A, Matchar DB, Moy CS, Mozaffarian D, Mussolino ME, Nichol G, Paynter NP, Soliman EZ, Sorlie PD, Sotoodehnia N, Turan TN, Virani SS, Wong ND, Woo D, Turner MB; American Heart Association Statistics Committee and Stroke Statistics Subcommittee. Executive summary: heart disease and stroke statistics--2012 update: a report from the American Heart Association. Circulation 2012;125:188-97.

2. McMurray JJ, Adamopoulos S, Anker SD, Auricchio A, Böhm M, Dickstein K, Falk V, Filippatos G, Fonseca C, Gomez-Sanchez MA, Jaarsma T, Køber L, Lip GY, Maggioni AP, Parkhomenko A, Pieske BM, Popescu BA, Rønnevik PK, Rutten FH, Schwitter J, Seferovic P, Stepinska J, Trindade PT, Voors AA, Zannad F, Zeiher A; ESC Guidelines for the diagnosis and treatment of acute and chronic heart failure 2012: The Task Force for the Diagnosis and Treatment of Acute and Chronic Heart Failure 2012 of the European Society of Cardiology. Developed in collaboration with the Heart Failure Association (HFA) of the ESC. ESC Committee for Practice Guidelines. Eur Heart J Fail 2012;14:803-869.

3. Mosterd A, Hoes AW. Clinical epidemiology of heart failure. Heart 2007;93:1137-46.

4. Fitzgerald AA, Powers JD, Ho PM, Maddox TM, Peterson PN, Allen LA, Masoudi FA, Magid DJ, Havranek EP. Impact of medication nonadherence on hospitalizations and mortality in heart failure. J Card Fail 2011;17:664-9.

5. De Geest S, Sabaté E. Adherence to long-term therapies: evidence for action. Eur J Cardiovasc Nurs 2003;2:323.

6. Böhm M, Schumacher H, Laufs U, Sleight P, Schmieder R, Unger T, Teo K, Yusuf S. Effects of nonpersistence with medication on outcomes in high-risk patients with cardiovascular disease. Am Heart J 2013;166:306-314.

7. Chobanian AV. Impact of nonadherence to antihypertensive therapy. Circulation 2009;120:1558-60.

8. Simpson SH, Eurich DT, Majumdar SR, Padwal RS, Tsuyuki RT, Varney J, Johnson JA. A meta-analysis of the association between adherence to drug therapy and mortality. BMJ 2006;333:15.

9. Rasmussen JN, Chong A, Alter DA. Relationship between adherence to evidence-based pharmacotherapy and long-term mortality after acute myocardial infarction. JAMA 2007;297:177-86.

10. Ewen S, Rettig-Ewen V, Mahfoud F, Böhm M, Laufs U. Drug adherence in patients taking oral anticoagulation therapy. Clin Res Cardiol 2014;103:173-82. 
11. Ambardekar AV, Fonarow GC, Hernandez AF, Pan W, Yancy CW, Krantz MJ; Get With the Guidelines Steering Committee and Hospitals. Characteristics and inhospital outcomes for nonadherent patients with heart failure: findings from Get With The Guidelines-Heart Failure (GWTG-HF). Am Heart J 2009;158:644-52.

12. Coronary Drug Project Research Group. Influence of adherence to treatment and response of cholesterol on mortality in the coronary drug project. $N$ Engl J Med 1980;303:1038-41.

13. Horwitz RI, Viscoli CM, Berkman L, Donaldson RM, Horwitz SM, Murray CJ, Ransohoff DF, Sindelar J. Treatment adherence and risk of death after a myocardial infarction. Lancet 1990;336:542-5.

14. Mazzaglia, Ambrosioni E, Alacqua M, Filippi A, Sessa E, Immordino V, Borghi C, Brignoli O, Caputi AP, Cricelli C, Mantovani LG. Adherence to antihypertensive medications and cardiovascular morbidity among newly diagnosed hypertensive patients. Circulation 2009;120:1598-605.

15. Yue Z, Cai C, Ai-Fang Y, Feng-Min T, Li C, Bin W. The effect of placebo adherence on reducing cardiovascular mortality: a meta-analysis. Clin Res Cardiol 2014;103:229-35.

16. Granger BB, Swedberg K, Ekman I, Granger CB, Olofsson B, McMurray JJ, Yusuf S, Michelson EL, Pfeffer MA, CHARM investigators. Adherence to candesartan and placebo and outcomes in chronic heart failure in the CHARM programme: double-blind, randomised, controlled clinical trial. Lancet 2005;366:2005-11.

17. Swedberg K, Komajda M, Böhm M, Borer JS, Ford I, Tavazzi L. Rationale and design of a randomized, double-blind, placebo-controlled outcome trial of ivabradine in chronic heart failure: the Systolic Heart Failure Treatment with the I(f) Inhibitor Ivabradine Trial (SHIFT). Eur J Heart Fail 2010;12:75-81.

18. Swedberg K, Komajda M, Böhm M, Borer JS, Ford I, Dubost-Brama A, Lerebours G, Tavazzi L; Ivabradine and outcomes in chronic heart failure (SHIFT): a randomised placebo-controlled study. SHIFT Investigators. Lancet 2010;376:875-85.

19. Böhm M, Borer J, Ford I, Gonzalez-Juanatey JR, Komajda M, Lopez-Sendon J, Reil JC, Swedberg K, Tavazzi L. Heart rate at baseline influences the effect of ivabradine on cardiovascular outcomes in chronic heart failure: analysis from the SHIFT study. Clin Res Cardiol 2013;102:11-22.

20. Böhm M, Swedberg K, Komajda M, Borer JS, Ford I, Dubost-Brama A, Lerebours G, Tavazzi L; SHIFT Investigators. Heart rate as a risk factor in chronic heart failure (SHIFT): the association between heart rate and outcomes in a randomised placebo-controlled trial. Lancet 2010;376:886-94. 
21. Osterberg L, Blaschke T. Adherence to medication. $N$ Engl $J$ Med 2005;353:487-97.

22. Ho PM, Bryson CL, Rumsfeld JS. Medication adherence: its importance in cardiovascular outcomes. Circulation 2009;119:3028-35.

23. Balkrishnan R. Predictors of medication adherence in the elderly. Clin Ther 1998;20:764-71.

24. Ammassari A, Trotta MP, Murri $R$, Castelli F, Narciso $P$, Noto $P$, Vecchiet $J$, D'Arminio Monforte A, Wu AW, Antinori A; AdICoNA Study Group. Correlates and predictors of adherence to highly active antiretroviral therapy: overview of published literature. J Acquir Immune Defic Syndr 2002;31:S123-7.

25. Vrijens $B$, Vincze $G$, Kristanto $P$, Urquhart J, Burnier M. Adherence to prescribed antihypertensive drug treatments: longitudinal study of electronically compiled dosing histories. BMJ 2008;336:1114-7.

26. Masoudi FA, Baillie CA, Wang Y, Bradford WD, Steiner JF, Havranek EP, Foody JM, Krumholz HM. The complexity and cost of drug regimens of older patients hospitalized with heart failure in the United States, 1998-2001. Arch Intern Med 2005;165:2069-76.

27. Gislason GH, Rasmussen JN, Abildstrom SZ, Schramm TK, Hansen ML, Buch P, Sørensen R, Folke F, Gadsbøll N, Rasmussen S, Køber L, Madsen M, TorpPedersen C. Persistent use of evidence-based pharmacotherapy in heart failure is associated with improved outcomes. Circulation 2007;116:737-44.

28. Fang J, Mensah GA, Croft JB, Keenan NL. Heart failure-related hospitalization in the U.S., 1979 to 2004. J Am Coll Cardiol 2008;52:428-34.

29. Goldberg RJ, Ciampa J, Lessard D, Meyer TE, Spencer FA. Long-term survival after heart failure: a contemporary population-based perspective. Arch Intern Med 2007;167:490-6.

30. Havranek EP, Masoudi FA, Westfall KA, Wolfe P, Ordin DL, Krumholz HM. Spectrum of heart failure in older patients: results from the National Heart Failure project. Am Heart J 2002;143:412-7.

31. Jong P, Yusuf S, Rousseau MF, Ahn SA, Bangdiwala SI. Effect of enalapril on 12-year survival and life expectancy in patients with left ventricular systolic dysfunction: a follow-up study. Lancet 2003;361:1843-8. 
32. Ford I, Murray H, Packard CJ, Shepherd J, Macfarlane PW, Cobbe SM; West of Scotland Coronary Prevention Study Group. Long-term follow-up of the West of Scotland Coronary Prevention Study. N Engl J Med 2007;357:1477-86.

33. Laufs U, Rettig-Ewen V, Böhm M. Strategies to improve drug adherence. Eur Heart J 2011;32:264-8.

34. Wu JR, Lennie TA, Dekker RL, Biddle MJ, Moser DK. Medication adherence, depressive symptoms, and cardiac event-free survival in patients with heart failure. $J$ Card Fail 2013;19:317-24.

35. Alosco ML, Spitznagel MB, Cohen R, Sweet LH, Josephson R, Hughes J, Rosneck J, Gunstad J. Better adherence to treatment recommendations in heart failure predicts improved cognitive function at a one-year follow-up. J Clin Exp Neuropsychol 2014;36:956-66. 


\section{Legends to figures}

\section{Figure 1}

Permanent stop of study medication over time on ivabradine or placebo.

\section{Figure 2}

Kaplan Meier curves for the primary endpoint (left), heart failure (HF)-hospitalization (middle) and cardiovascular (CV) death (right) in patients adherent or non-adherent to ivabradine or placebo.

\section{Figure 3}

Hazard ratios on non-adherence on outcomes on placebo (left) or ivabradine (right). CV: cardiovascular; HF: heart failure

\section{Figure 4}

Kaplan Meier curves for the treatment effect of ivabradine vs placebo on the primary endpoint (A, composite of cardiovascular death and heart failure hospitalization), heart failure (HF) hospitalization (B), cardiovascular (CV) death (C).

\section{Figure 5}

Hazard ratios of the effect of ivabradine versus placebo in patients becoming nonadherent or staying adherent during follow-up.

CV: cardiovascular; HF: heart failure

\section{Figure 6}

Kaplan Meier curves for becoming non-adherent after a previous heart failure hospitalization (A) or a previous cardiovascular hospitalization (B) on placebo (left) or ivabradine (right).

\section{Figure 7}

Hazard Ratio for becoming non-adherent after a previous heart failure hospitalization (A) or a previous cardiovascular hospitalization (B) on placebo (left) or ivabradine (right). 


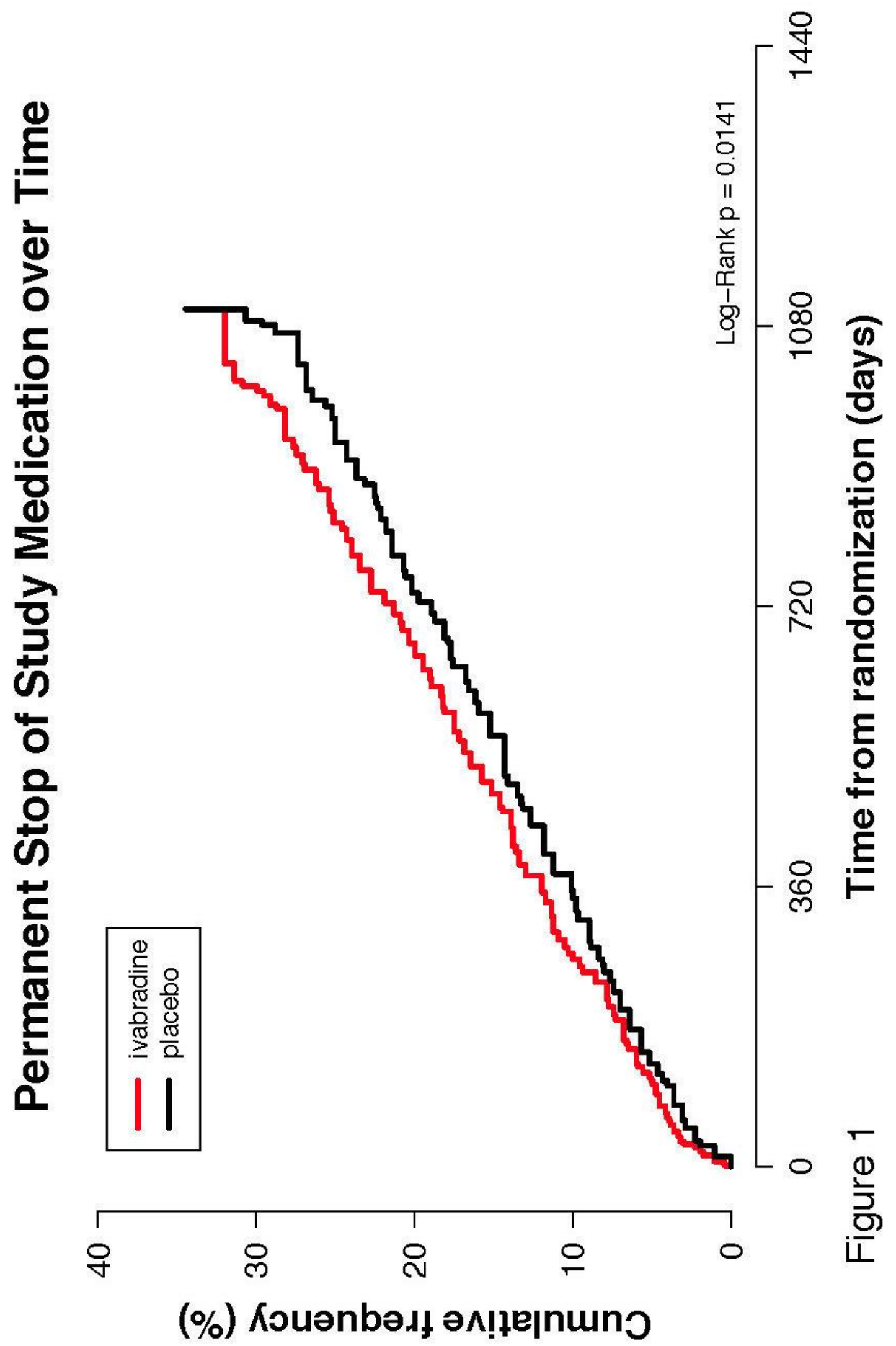




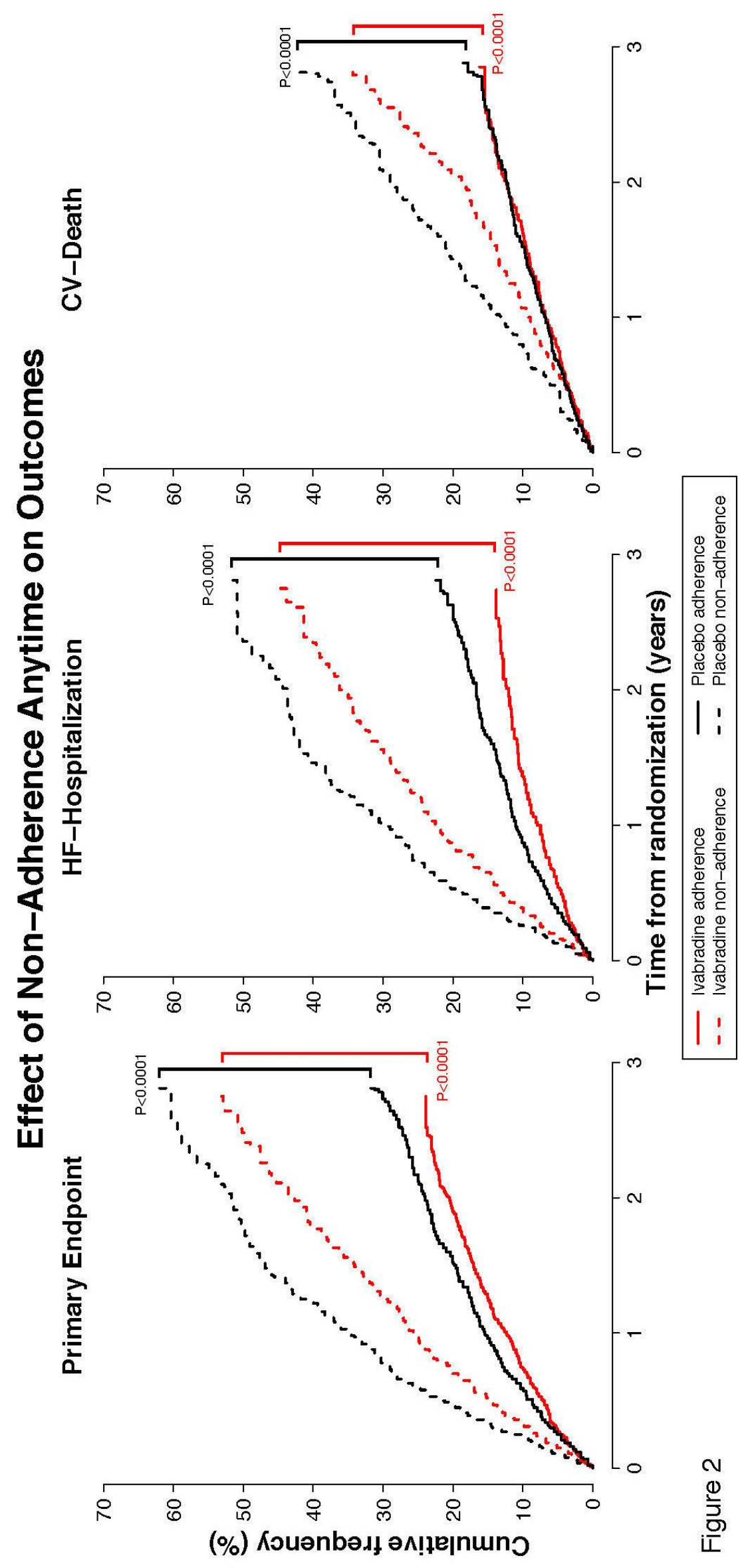




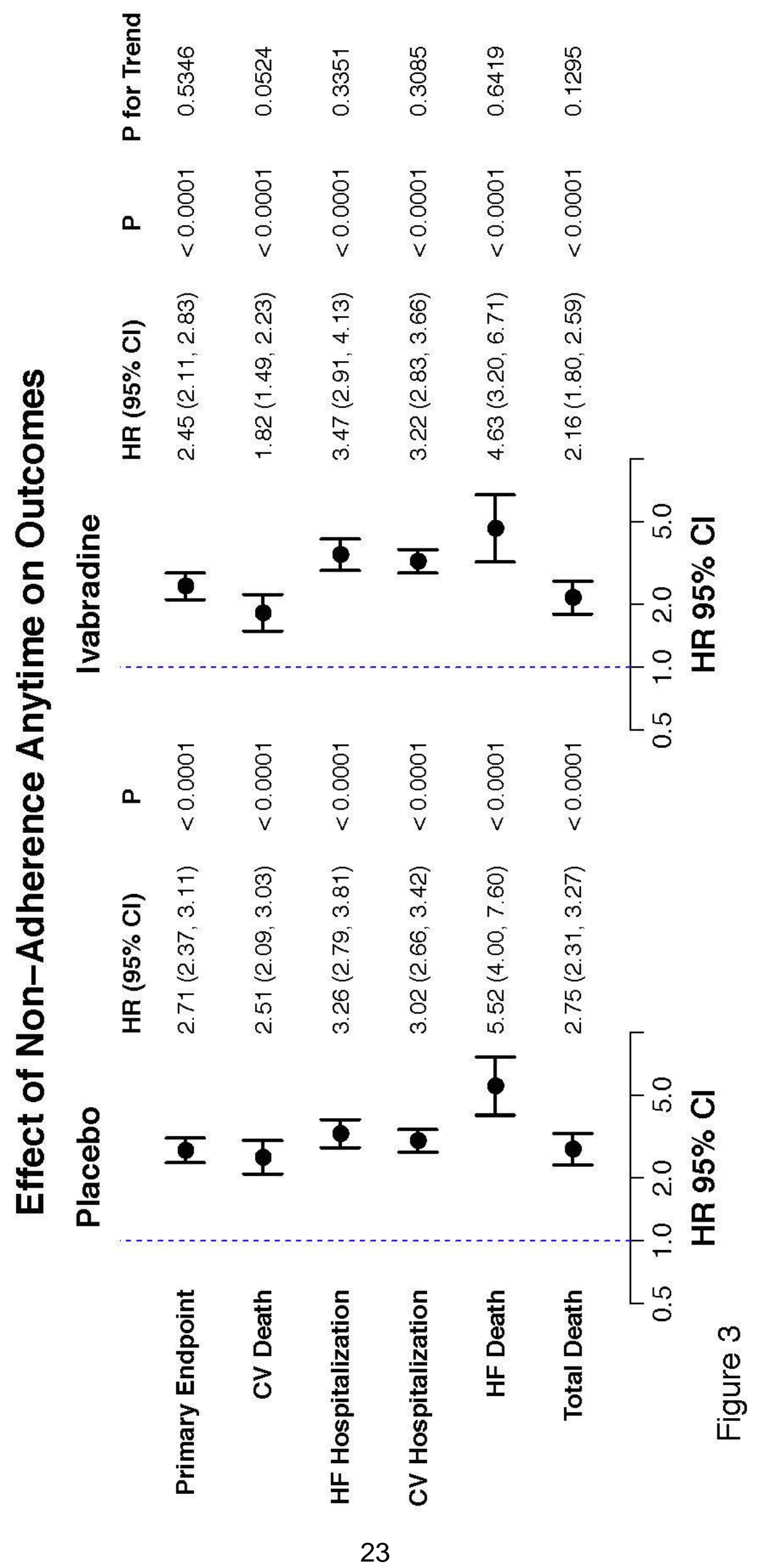




\section{Treatment Effect in Patients Anytime Non-Adherent}
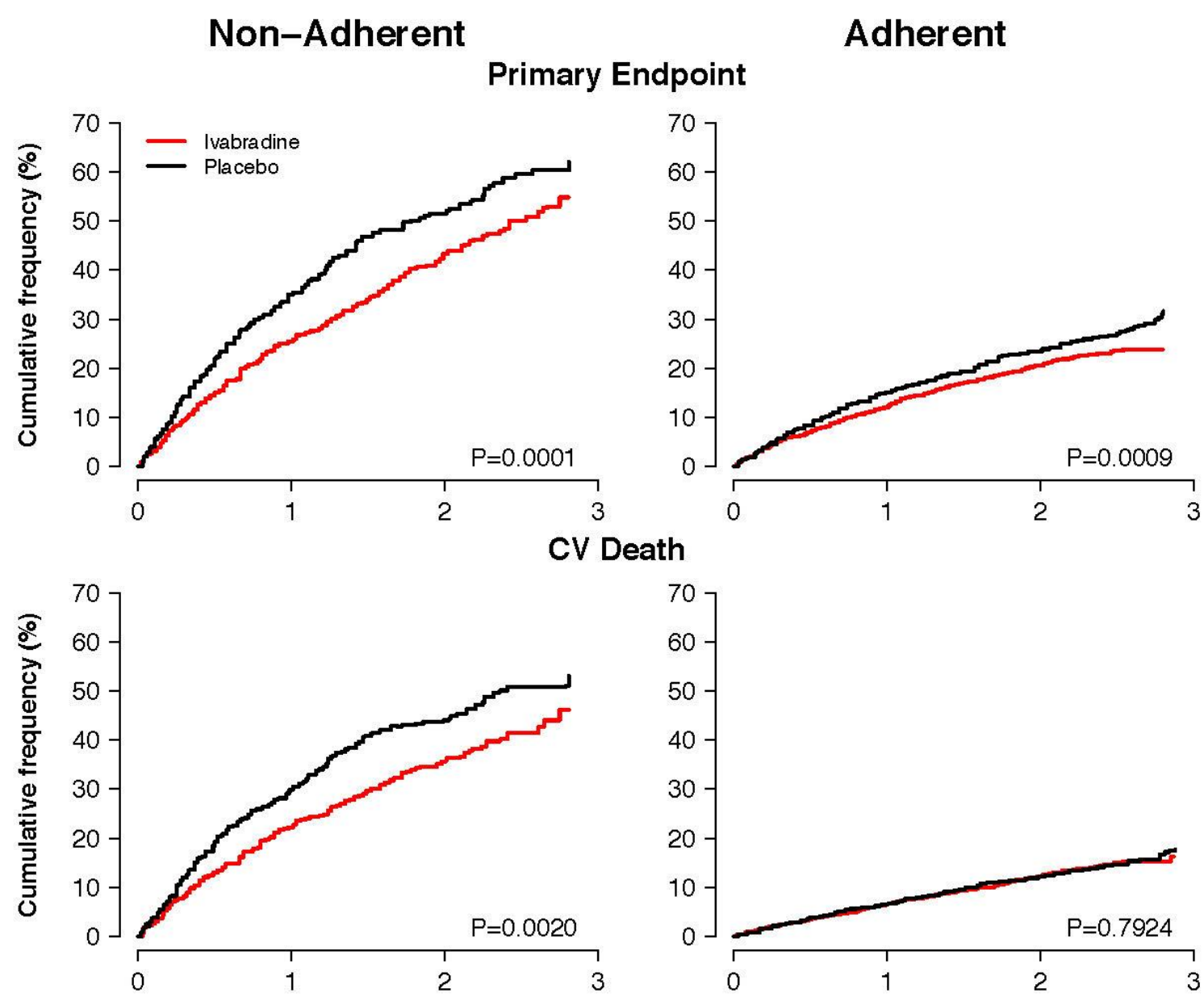

HF Hospitalization
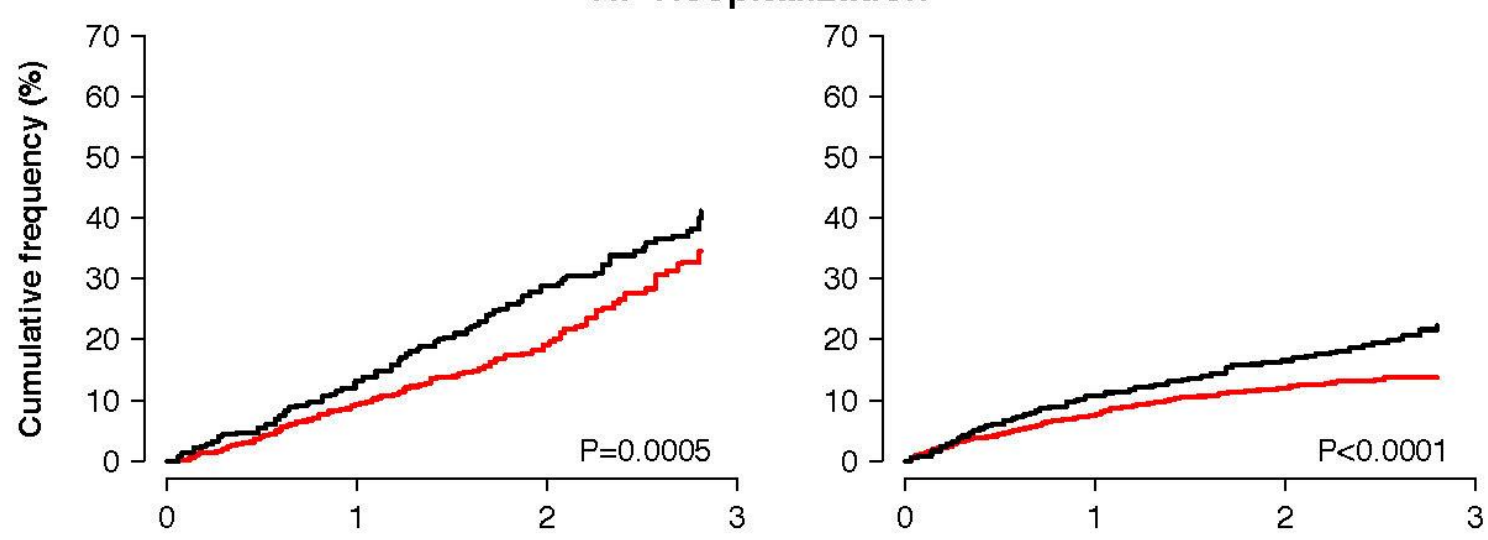

Figure 4

Time from randomization (years) 


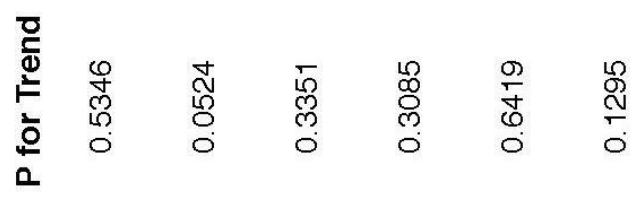

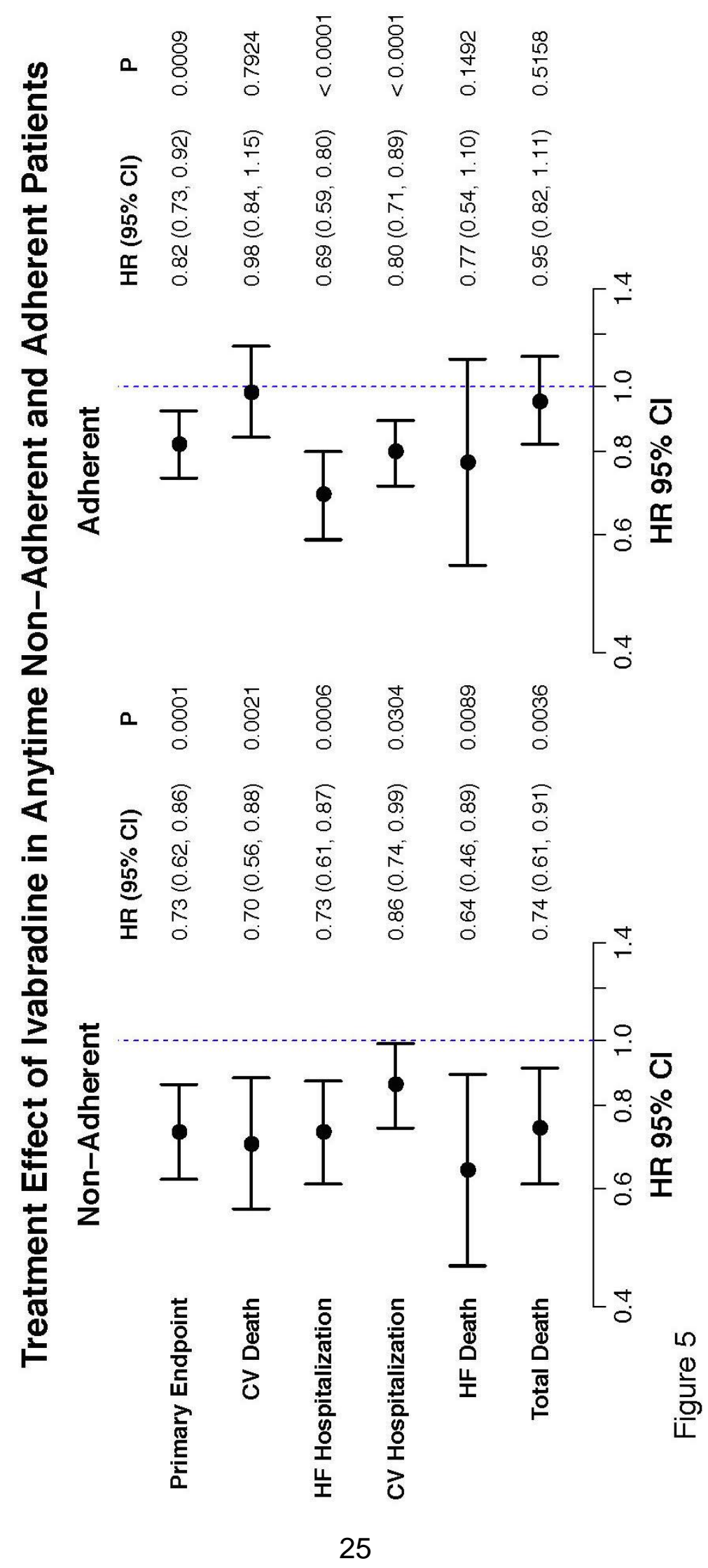




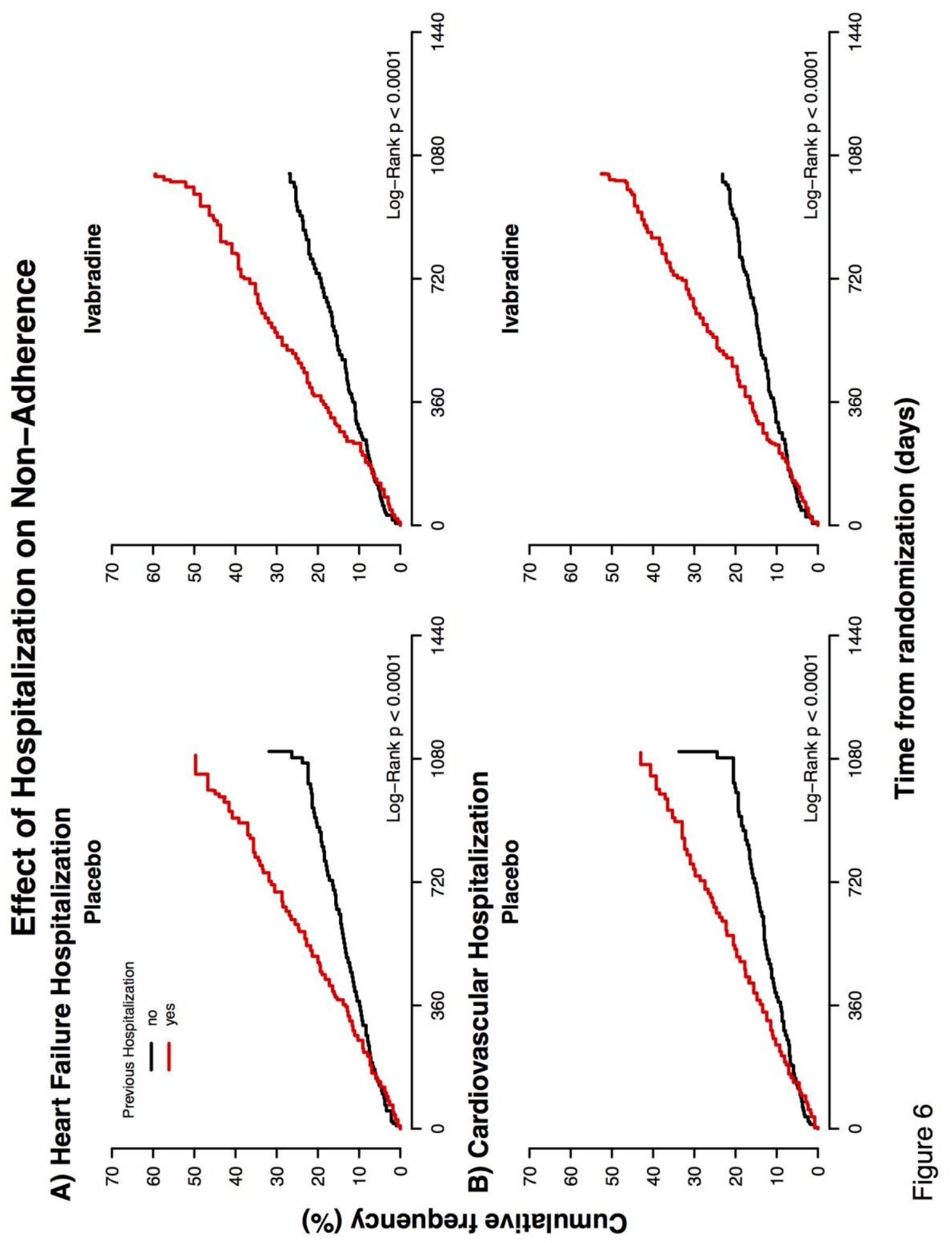




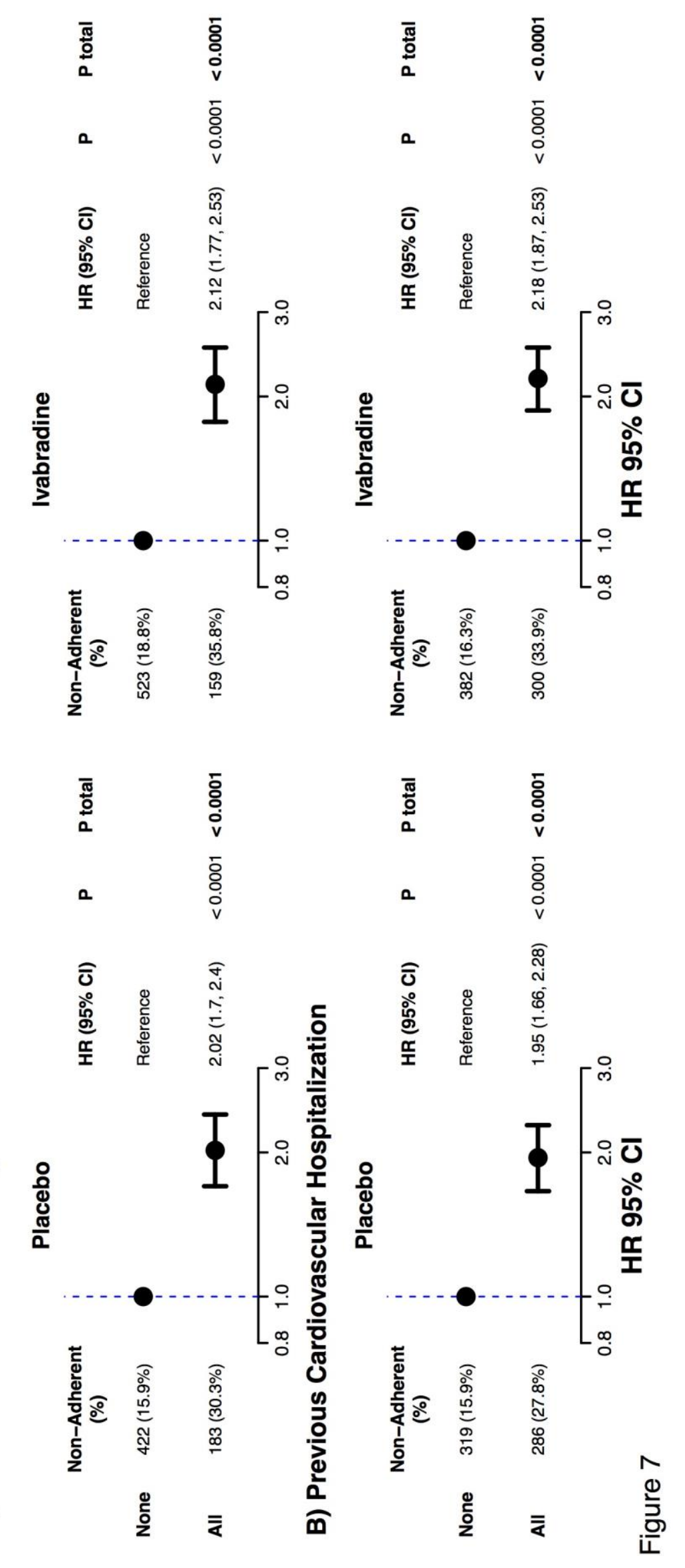

